\title{
Natural Treatment of Woolen Processing Industry Wastewater
}

\author{
Sajid Qurashi ${ }^{1}$, Omprakash Sahu ${ }^{2, *}$ \\ ${ }^{1}$ Department of Textile Engineering, Wollo University, Ethiopia \\ ${ }^{2}$ Department of Chemical Engineering, KIOT, Wollo University, Ethiopia \\ Tel: +251933520653 \\ *E-mail address: ops0121@gmail.com
}

\begin{abstract}
Wastewater treatment is becoming ever more critical due to diminishing water resources, increasing wastewater disposal costs, and stricter discharge regulations that have lowered permissible contaminant levels in waste streams. The ultimate goal of wastewater management is the protection of the environment in a manner commensurate with public health and socio-economic concerns. The aim of our study is to use natural occurring plant (Pistia stratiotes) to reduce the chemical oxygen demand and color from the industrial waste water. It was found that $120 \mathrm{mg} / 1$ of Chemical oxygen demand and $85 \mathrm{mg} / \mathrm{l}$ of color reduction was observed with Pistia stratiotes.
\end{abstract}

Keywords: Biological oxygen demand; Chemical oxygen demand; Treatment

\section{INTRODUCTION}

Industrialization plays a vital role in the growth and development of any country. Different industries have their own importance. But with the growth of industrialization some drawback are also, especially environmental problem. Among all the industry woolen industries have also major contribution for increasing the pollution level in the environment as well as in the foreign income.

Wool is increasingly seen by caring consumers as a sustainable lifestyle choice for fashion and interiors [1]. Consequently, fashion designers and retailers are asking textile manufacturers ever more searching questions about provenance, origin and sustainability. Sustainability along the supply chain from farm to fashion is an increasingly important element in areas relating to Corporate Social Responsibility.

Wool waste originates from scouring, carbonizing, bleaching, dyeing, oiling, fulling, and finishing operations. Impurities of raw wool, consisting mainly of wool grease and other foreign matter are removed by scouring the wool in hot detergent alkali solution [2]. Some wool is scoured by organic solvents. Various methods of grease recovery or cracking of grease containing waste has been suggested.

Wool grease may be recovered from the surrounding waste by centrifuging, coagulation or floatation, and may be processes individual plants recover grease chiefly by centrifuging, coagulation either by sulphuric acid or by calcium or aluminium salts is also employed [3]. 
Carbonising is a process in which hot concentrated acids are used to convert vegetable matters in the wool into loose charred particles, followed by mechanical dusting of the same. Wool may be dyed at any stage either as raw stock, or after spinning and weaving.

Normally hot dye solutions are circulated through the wool, backed in a metal container. In oiling, usually olive oil or a barg-oil -mineral oil mixture is sprayed over the wool to aid in the spinning. Fulling is an operation where the loosely woven wool from the loom is shrunk into a tight closely woven cloth. To aid this process, chemicals like soda ash, soap etc., are used. Excess fulling chemicals, all of the oil etc are washed out of the fabric in a finishing process. Wastes from a dyeing and finishing process are contributed by the spent liquors and by subsequent washing of wool after bleaching, dyeing, and finishing.

In the literature up to now, in order to determine treatment processes and methods, conventional treatment processes such as coagulation/flocculation process [3], chemical/physical oxidation [4], activated sludge [5,6] and adsorption [7] and advanced treatment methods such as advanced oxidation [8], membrane process [9], Fenton process [10], electrochemical oxidation [11], electrolytic treatment [12] and reverse osmosis [13] have been applied.

Conventional solutions are inappropriate and expensive because the infrastructures and skilled labor are lacking. Development of aquatic plants-based wastewater treatment systems is now recognized as suitable alternative to cost-effectively and safely treat sewage [14]. The scientific basis and the technical feasibility of this eco-technology are well established and abundant literature exists on the potentials of several aquatic plants to clean water especially in North America and Europe [15]. The tropical regions offer several advantages for the development of such technology. Aquatic plants are abundant and the suitable climate means that processes are optimum and operational all year round. A macrophytic lagoon system was constructed in Yaounde for domestic sewage treatment from a population of 650. It consists of 8 serially arranged ponds and operates in two phases.

The first is a decantation digestion phase in which substances are partially decomposed by microorganisms, producing a liquid effluent and a mixture of gazes which escape through small fissures on the thick layer of accumulated organic matter to the atmosphere. Some emergent plants like Cyperus papyrus and Ipomoea aquatica are cultivated on that layer to enhance the activity of some microorganisms [16,17].

After this primary process, sewage flows gently by gravity through PVC pipes to the macrophytic lagoon phase in which Pistia stratiotes is the main system supporting plant. Its abundant root system and stolons act as filters, trapping suspended matters and providing a surface for the adhesion and the proliferation of microorganisms. Plants then absorb biodegradation products and are constantly eliminated from the system by regular harvest of part of the crop generated. Treated water is discharged into a natural wetland area dominated by several aquatic plants whose potentials in wastewater Phytoremediation are recognized [18].

This paper presents some results on the performances and management strategies of Pistia stratiotes in the macrophytic lagoon phase, the overall efficiency and some guidelines for the exploitation of such a system in the tropical context.

\section{MATERIAL AND METHODS}

\section{1. Material}

The experimental plant arrange from the local pond. Pistia stratiotes also known as Jalkumbhi, is an aquatic plant, stoloniferous, floating on lakes, streams, and stagnant water ponds and in lime-rich water, throughout India. It is distributed in the tropical and subtropical region of Asia, Africa, and America. Four varieties are distinguished. The Indian variety is 
known as varcuneta. It is propagated by seeds or more rapidly by stolons. It forms a dense mat on the water surface and causes serious clogging on water ways. It is also responsible for harboring mosquito larvae, which carry the malarial parasites. It also flowers in hot season and fruits appear after the rain. The picture of Pistia stratiotes shown in Fig. 1.

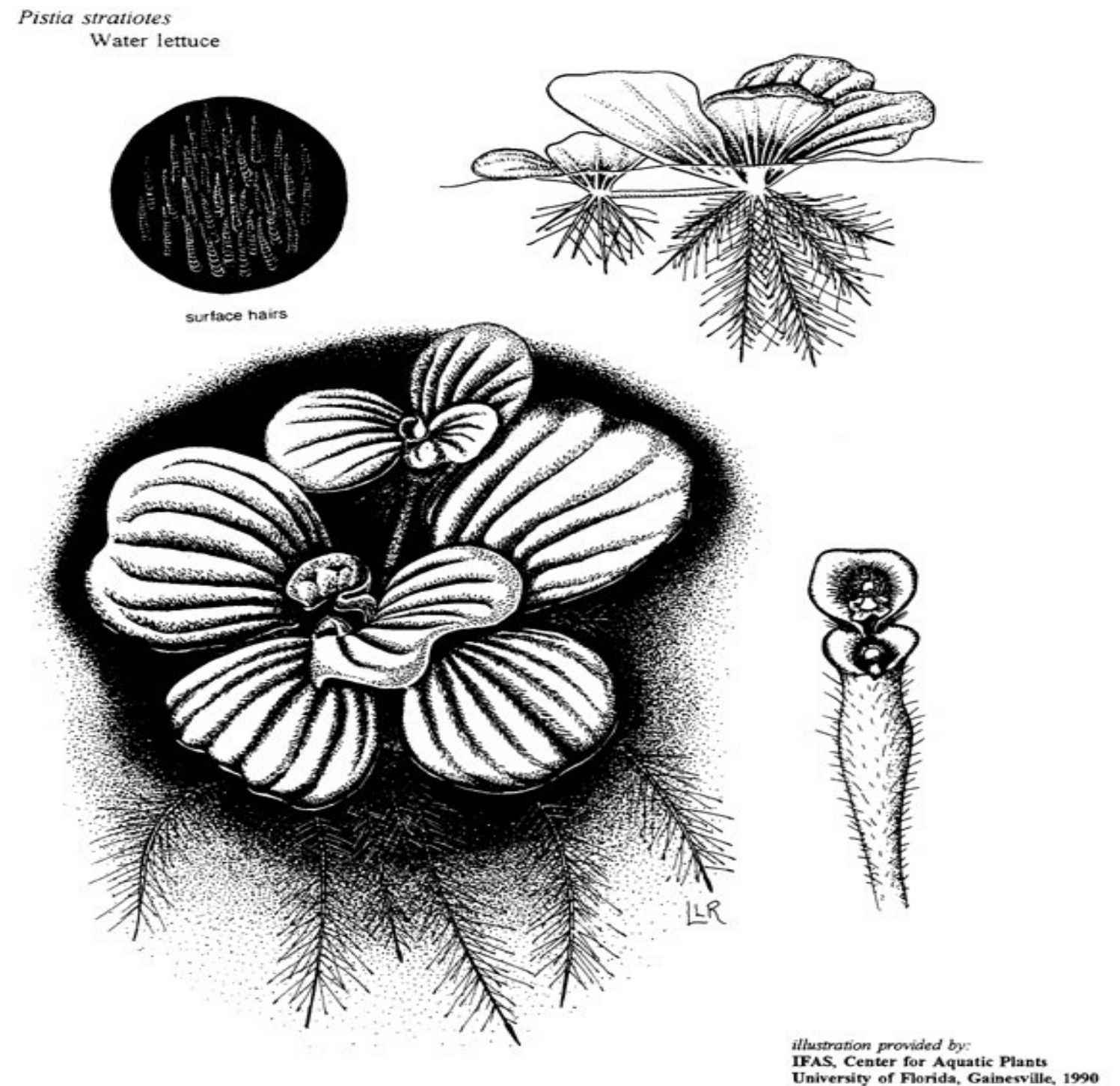

Fig. 1. Picture of Pistria stratiotes.

The characterstic of woolen waste water is mention Table no. 1. It was found that the pollutant parmeter are much higher than dischargeable limit. 
Table 1. The quality parameters of Wool Processing Industries.

\begin{tabular}{|c|c|c|c|}
\hline S.No & Characteristics & $\begin{array}{c}\text { Quality of } \\
\text { woolen industry } \\
\text { (mg/l) }\end{array}$ & $\begin{array}{l}\text { Tolerance } \\
\text { Limit }\end{array}$ \\
\hline 1 & Suspended Solids, mg/L & 350 & 100 \\
\hline 2 & $\begin{array}{l}\text { Biochemical Oxygen Demand (5 days at } 20{ }^{\circ} \mathrm{C} \text { ), } \\
\mathrm{mg} / \mathrm{L}\end{array}$ & 960 & 100 \\
\hline 3 & Oil and grease, $\mathrm{mg} / \mathrm{L}$ & 35 & 10 \\
\hline 4 & Chemical Oxygen Demand, mg/L & 2150 & 250 \\
\hline 5 & Total Chromium (as $\mathrm{Cr}$ ), $\mathrm{mg} / \mathrm{L}$ & 12.5 & 2 \\
\hline 6 & Sulphide (as S), mg/L & 10 & 2 \\
\hline 7 & Phenolic compounds (as $\mathrm{C}_{6} \mathrm{H}_{5} \mathrm{OH}$ ), mg/L & 17 & 5 \\
\hline 8 & $\mathrm{pH}$ Value & 10.8 & $5.5-9.0$ \\
\hline 9 & Temperature ${ }^{\circ} \mathrm{C}$ & 55 & 30 \\
\hline
\end{tabular}

\section{2. Methods}

The treatment system is constructed by concert walls. The waste water was collecting in the first step of treatment in the collecting tank whose capacities are $50000 \mathrm{~L}$. In the second step the waste water was allowed to flow in bed one (B1) here the water circulated with the help of baffle and Rention time 10 days.

After first bed the wastewater allowed to flow in second bed (B2) here the retention time was 8days, similarly for B3 6 days, B4 4 days and B5 2 days respectively. The flow rate was controlled by the automatic valve on the passage.

Finally the waste water is filter with the sand and allows discharging for the agriculture purpose. The solid waste on generated on the above filter was used as manure. The systemic flow diagram of experiment is shown in Fig. 2. 


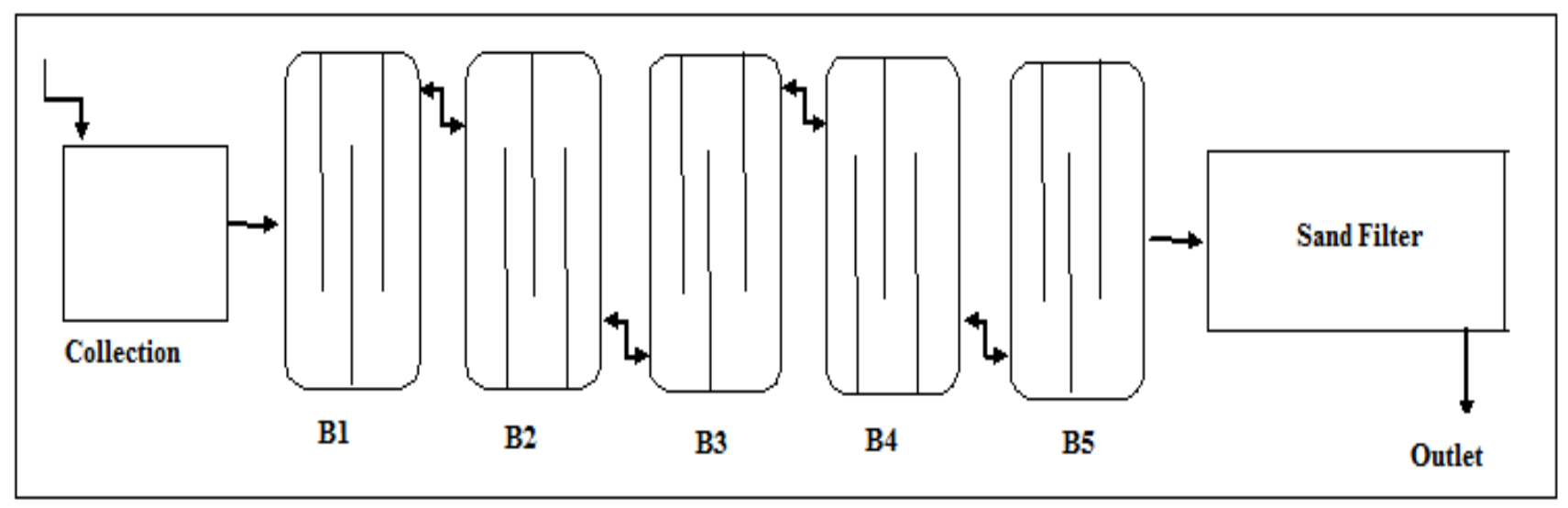

Fig. 2. Flow digram of experimental setup.

\section{3. Analysis}

The study was done by a comprehensive study through primary data collection and secondary literature survey for secondary data collection. First of all the study area was selected and a reconnaissance survey took place.

Then to obtain basic ideas of the quality, characteristics and chemical composition of the effluent of cafeteria seven samples were collected. This sampling method involves purposive or deliberate selection of particular units of the sampling area for constituting a sample, which represent the universe.

For physical and chemical analysis of those effluent samples a number of sophisticated instruments were used and standards methods were followed. To measure the effluent quality of the collected sample the following analysis were performed in the laboratory of Environmental Science Discipline.

\section{RESULT DISCUSSION}

\section{1. Effect of retention time}

To determine the effect of retention time on COD and BOD was carried out at B1, which shown in Fig. 3. It was found that first day the COD $2000 \mathrm{mg} / 1$ and BOD $880 \mathrm{mg} / \mathrm{l}$ reduction. The COD 1970, 1900, 1875, 1825, 1790, 1720, 1650, 1545, $1485 \mathrm{mg} / \mathrm{l}$ and BOD $740,710,685,660,610,575,545,500,490 \mathrm{mg} / 1$ was observed at $2,3,4,5,6,7,8,9$, and 10 days respectively. This reduction of pollutant is due to utilization of waste biomass as nutrients for their own growth.

Similarly the effect of pollutant reduction was observed in bed two (B2). In the section maximum retention time was 8days which is shown in Fig. 4. After completing the 10 days on $\mathrm{B} 1$ the waste water was allowed to flow in B2.

The chemical oxygen demand 1350, 1280, 1235, 1175, 1120, 950, 835, $765 \mathrm{mg} / \mathrm{l}$ and biological oxygen demand 480, 450, 425, 405, 390, 372, 360, $340 \mathrm{mg} / \mathrm{l}$ was observed at 1, 2, $3,4,5,6,7$ and $8^{\text {th }}$ days. 


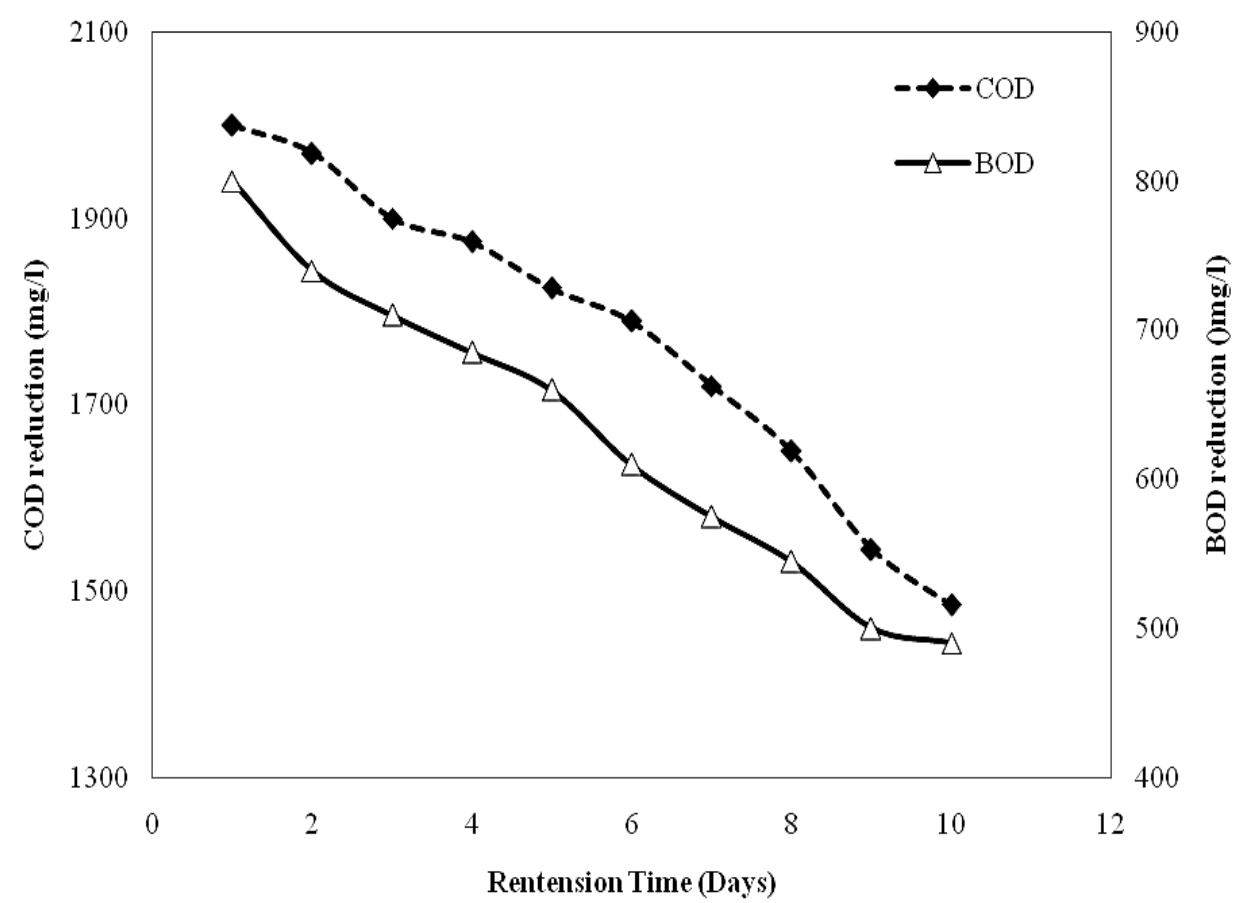

Fig. 3. Effect of rentension time in bed first (B1).

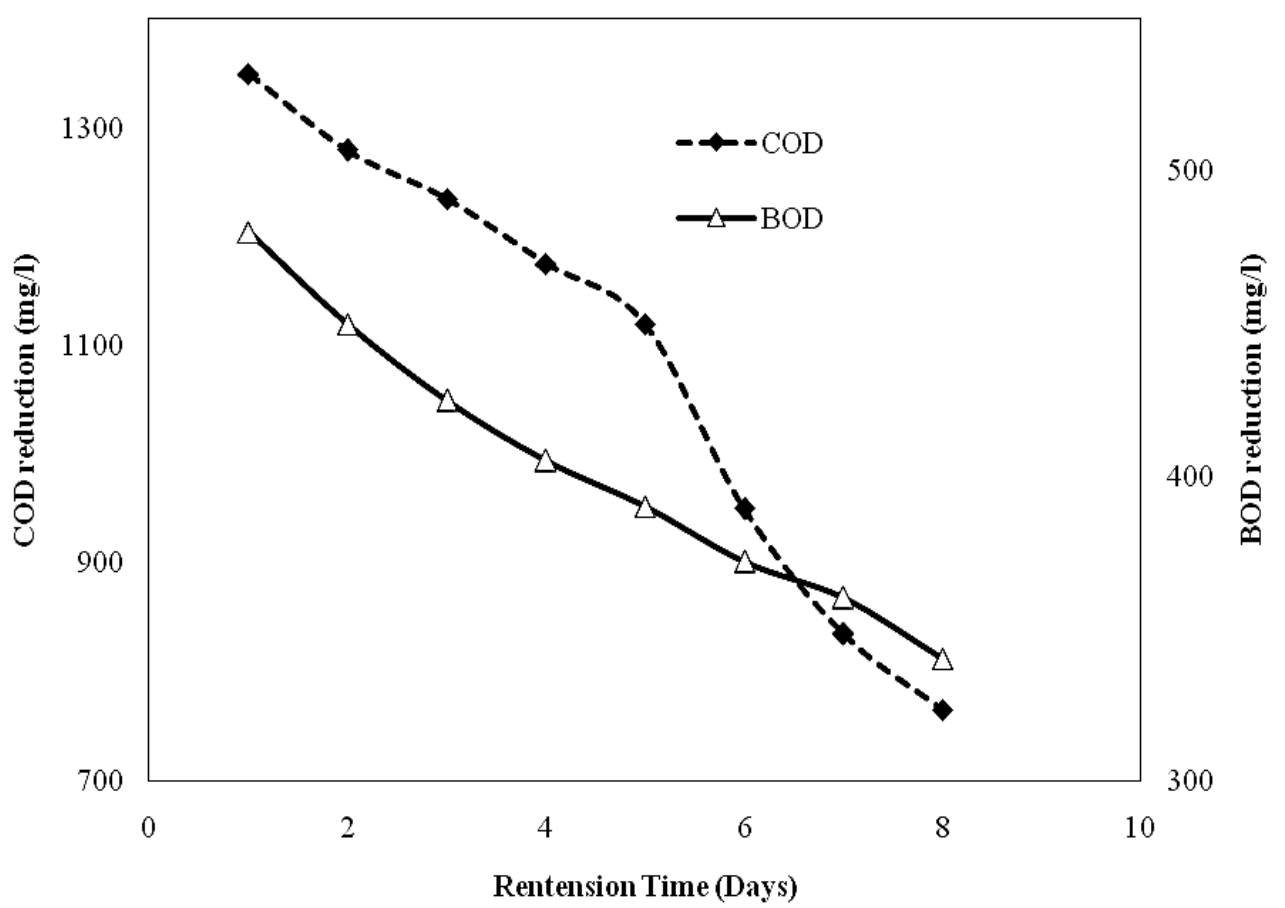

Fig. 4. Effect of rentension time in bed second (B2). 
For the bed three (B3) the maximum retention time was 6 days. The reduction of BOD and COD was shown in Fig. 5. The COD 690, 625, 575, 570, 475, $400 \mathrm{mg} / \mathrm{l}$ and BOD 310, $295,270,235,210,180 \mathrm{mg} / 1$ was found at $1,2,3,4,5$ and $6^{\text {th }}$ days of the treatment.

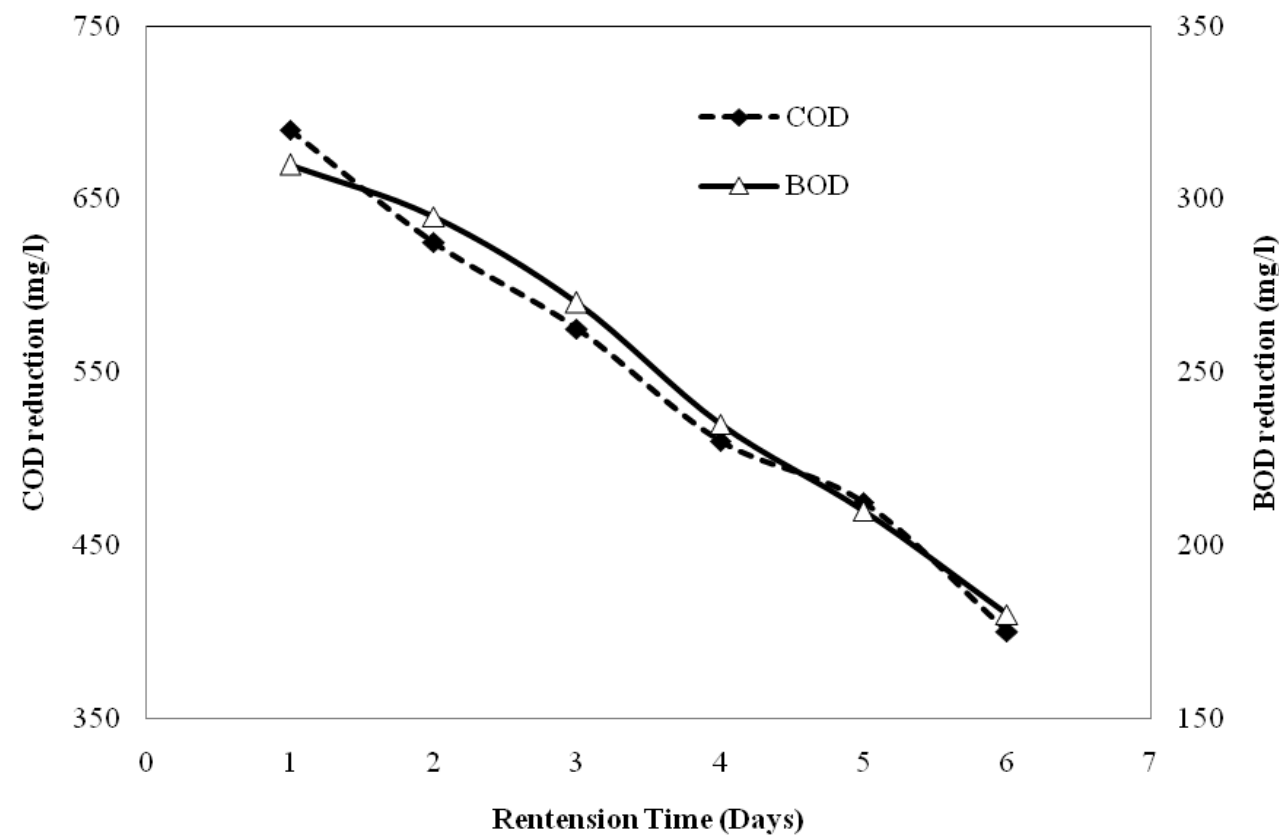

Fig. 5. Effect of rentension time in bed third (B3).

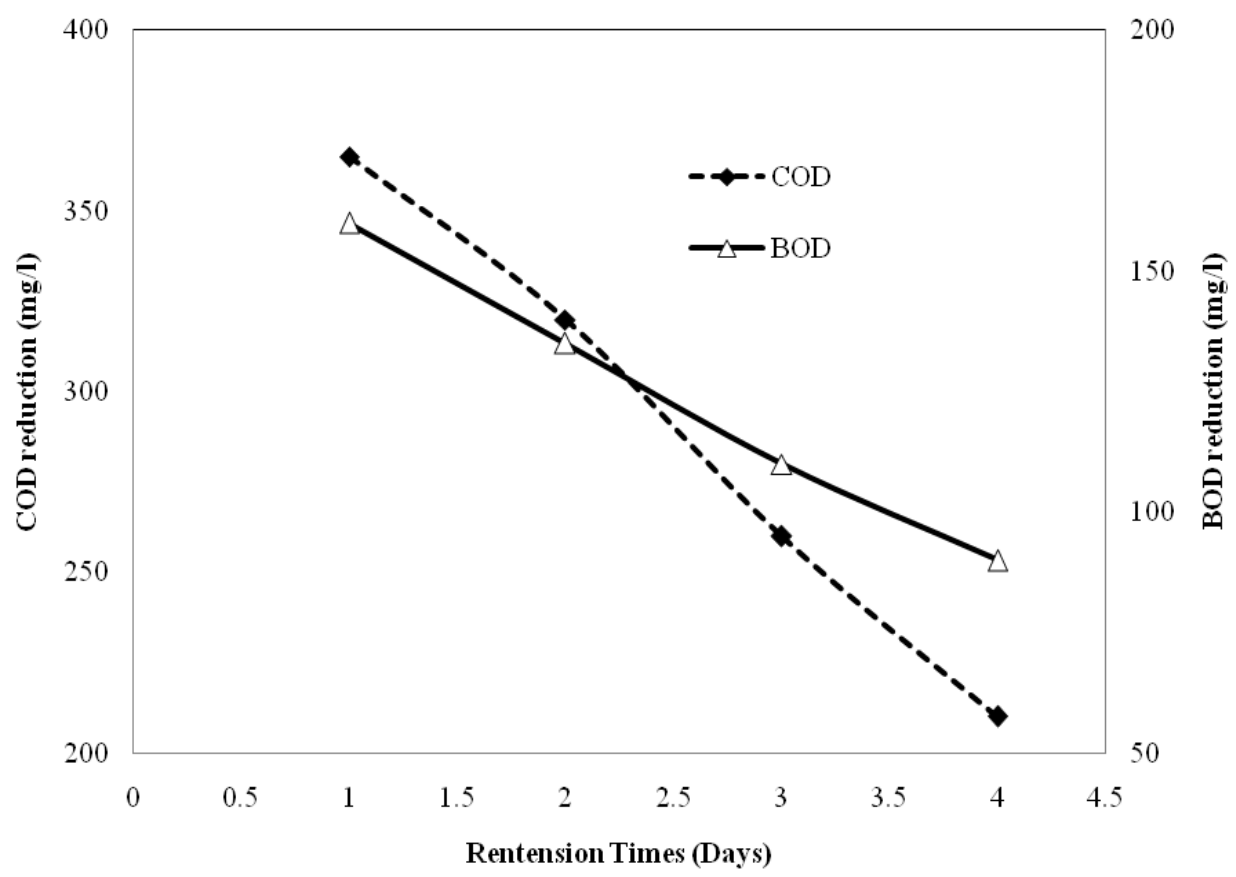

Fig. 6. Effect of rentension time in bed fourth (B4). 
For the fourth treatment bed (B4) the maximum 4 days was decided. The reduction of pollutant is shown in Fig. 6. The COD reduction 365, 320, 260, $210 \mathrm{mg} / \mathrm{l}$ and BOD 160, 135, $110,90 \mathrm{mg} / \mathrm{l}$ was observed at $1,2,3$ and $4^{\text {th }}$ days of the treatment.

Finally the wastewater was allowed to stay for 2 days in B5 (fifth treatment bed), which is shown in Fig. 7. The reduction of COD 180, $120 \mathrm{mg} / \mathrm{l}$ and BOD 85, $65 \mathrm{mg} / \mathrm{l}$ was observed was 1 and $2^{\text {nd }}$ day of the treatment. The sugar is an important constituent manufactured during photosynthesis and breakdown during respiration by plants. The lower sugar level may be due to lowered synthesis or diversion of the metabolites to other synthesis processes thus reduced sugar content in polluted plants might have resulted due to the adverse effect of toxicity on the process of photosynthesis. Excess concentration of pollution caused reduction in total sugar content in Pistia stratiotes plants.

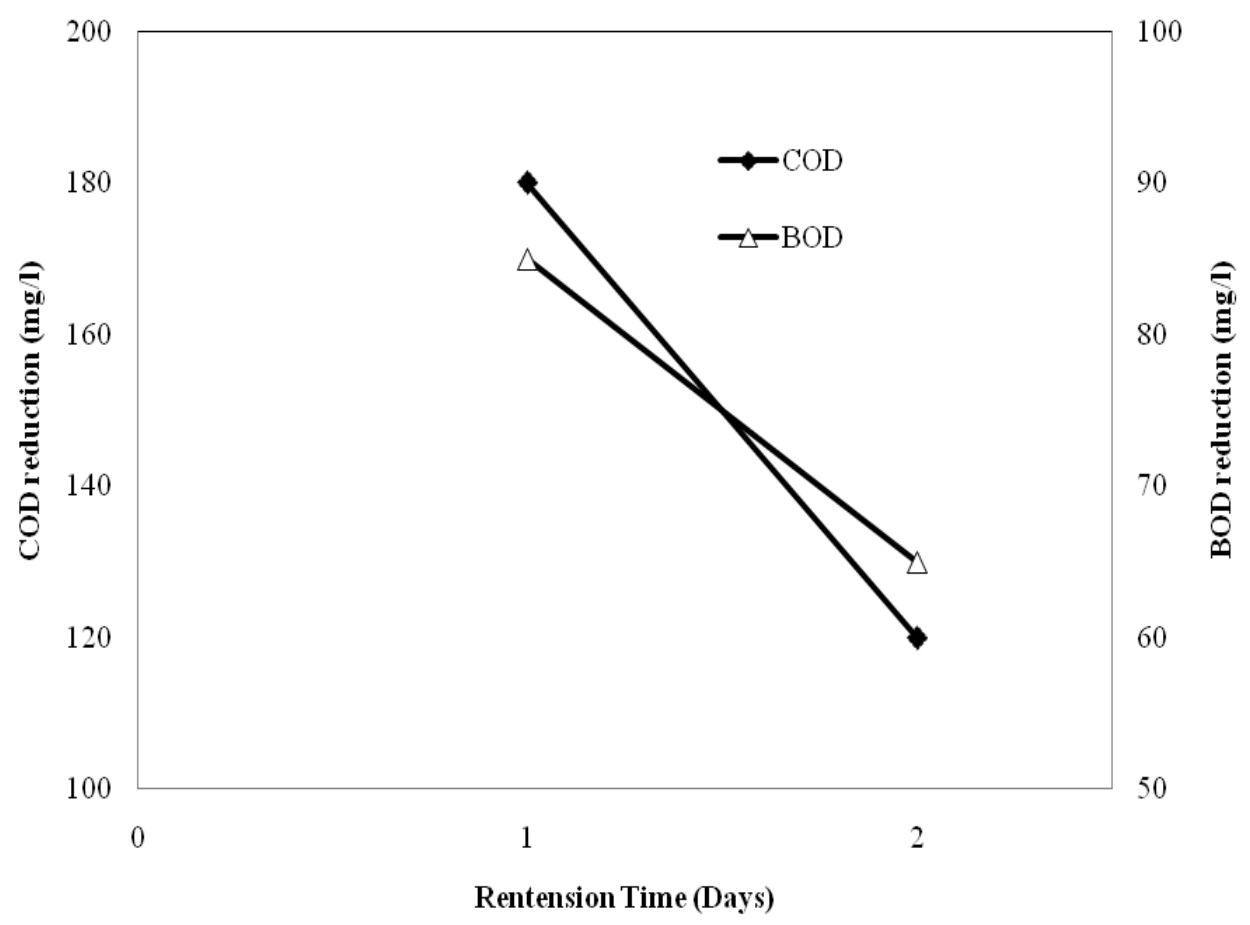

Fig. 7. Effect of rentension time in bed fifth (B5).

\section{2. Scanning Electron Micrograph}

After drying the sludge generated from sand filter was dried and studied for the scanning electron micrograph, which is shown Fig. 6. It was observed the residue have crystalline structure. The scanning electron microscope of wastewater before and after treatments was investigated which is shown Fig. 8. It was found that before treatment the sludge are look compact and rigid. After treatment the sludge generated looks jelly type, it is due to absorbance of pollutant by Pistia stratiotes roots which are trapped the pollutant and bind up in like rope. 


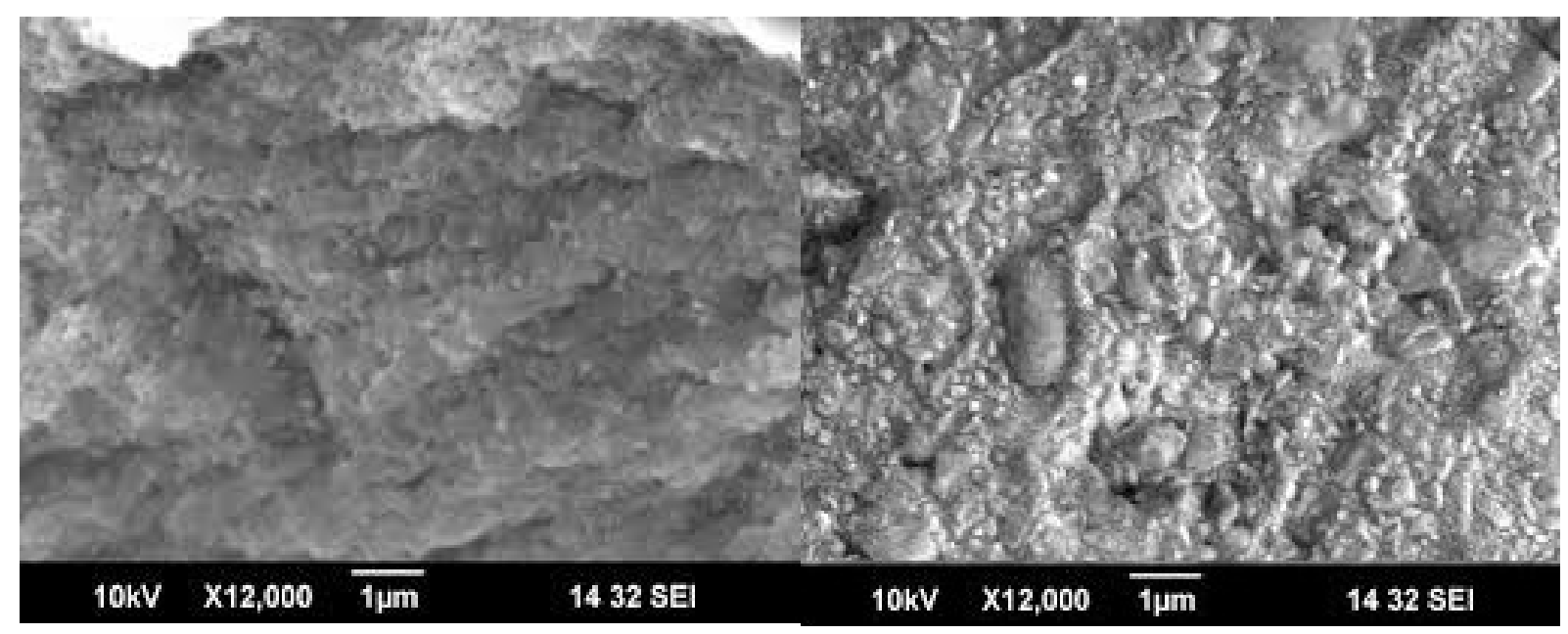

Fig. 8. Scanning electron micrography studied of generated sludge.

\section{CONCLUSION}

Pistia stratiotes and the associated microorganisms are those from the surrounding habitat, hence already adapted to the sewage. This plant shows rapid growth all through the study period, but growth attributes are higher in the last ponds than the first ones. The evolution of these parameters situates the optimal period of growth (hence important absorption and accumulation of nutrients) between the 15th and the 20th days after cultivation. This system improves some water parameters by more than $70 \%$.

The operation of a Pistia based sewage treatment system is therefore a simple and efficient solution to treat domestic sewage especially in the tropics. This efficiency is linked to the careful management of the plant in the system. Since the plant rapidly grows in the first 15-20 days to form a crowded mat and start dying off thereafter, the management involves periodic harvesting of part of the elaborated biomass after every 15 days.

\section{Reference}

[1] METCALF and EDDY INC., "Wastewater engineering treatment disposal”, Mc GrawHill Inc., New York, 1991, 178-195.

[2] Zhuravleva L. L., Artemenko S. E. and Ustinova T. P., "Selection of methods of industrial wastewater treatment", Fibre Chemistry 36(2) (2004) 156-159.

[3] Amuda O. S. and Amoo I. A., "Coagulation / flocculation process and sludge conditioning in beverage industrial wastewater treatment", Journal of Hazardous Materials 141(3) (2007) 778-783.

[4] Bertanza G., Collivignarelli C. and Pedrazzani R., "The role of chemical oxidation in combined chemicalphysical and biological processes: Experiences of industrial wastewater treatment", Water Science and Technology 44 (5) (2001) 109-116.

[5] Arslan A. and Ayberk S., "Characterization and biological treatability of "Izmit industrial and domestic wastewater treatment plant" wastewaters", Water $S A$ 29(4) (2003) 451-456. 
[6] Pala A. and Tokat E., "Color removal from cotton textile industry wastewater in an activated sludge system with various additives", Water Research 36 (2002) 2920-2925.

[7] Krishnan S. S., Cancilla A. and Jervis R. E., "Industrial wastewater treatment for toxic heavy metals using natural materials as adsorbants", Journal of Radioanalytical and Nuclear Chemistry 110(2) (1987) 373-378.

[8] Gunukula R. V. B. and Titlebaum M. E., "Industrial wastewater treatment by an advanced oxidation process", Journal of Environmental Science and Health Part AToxic/Hazardous Substances \& Environmental Engineering 36(3) (2001) 307-320.

[9] Juang L. C., Tseng D. H. and Lin H. Y., "Membrane processes for water reuse from the effluent of industrial park wastewater treatment plant: A study on flux and fouling of membrane", Desalination 202(1-3) (2007) 302-309.

[10] Badawy M. I. and Ali M. E. M., "Fenton's peroxidation and coagulation processes for the treatment of combined industrial and domestic wastewater", Journal of Hazardous Materials 136(3) (2006) 961-966.

[11] Szpyrkowicz L., "Application of electrochemicaloxidation for treatment of industrial wastewater - The influence of reactor hydrodynamics on direct and mediated processes", Journal of Chemical Technology and Biotechnology 81(8) (2006) $1375-1383$.

[12] Edwards F. G., Fendley D. L. and Lundford J. V., "Electrolytic treatment of an industrial wastewater from a hosiery plant", Water Environment Research 78(4) (2006) 435-441.

[13] Into M., Jonsson A. S. and Lengden G., "Reuse of industrial wastewater following treatment with reverse osmosis", Journal of Membrane Science 242(1-2) (2004) 21-25.

[14] El-Gohary F. A., Wahaab R. A., Nasr F. A. and Ali H. I., "Three Egyptian industrial wastewater management programmes", The Environmentalist 22 (2002) 59-65.

[15] Agendia P., Kengne I., Fonkou T., Mefenya R. et Sonwa D. Production du compost à partir de la biomasse de Pistia stratiotes utilisée pour l'épuration des eaux usées domestiques à Yaoundé (Cameroun). Cahiers Agricultures 6 (2007) 15-19.

[16] Reddy, K., R., and Smith, W., H., Aquatic plants for water treatment and resource ecovery. Magnolia Publishing Inc. 2010, 1032.

[17] Hubac, J., M., Beuffe, H., Blake, G., Corradi, M., Dutartre, A., Vaucouloux, Vuillot, M., Les plantes aquatiques utiles: les lentilles d'eau (Lemnacées), Association Française pour l'Etude des Eaux, Paris 1984.

[18] Brix, H., and Schierup, H., H., Sewage treatment in constructed reed beds - Danish experiences. Wat. Sci. Tech., Brighton 21 (2009) 1665-1668. 